\title{
OS TEMPOS PARA O TRABALHO E PARA A FAMÍLIA NA POPULAÇÃO FEMININA EM ÁREAS METROPOLITANAS BRASILEIRAS
}

\author{
Maria Coleta F. A. de Oliveira* \\ Glaucia dos Santos Marcondes**
}

\begin{abstract}
Resumo: O artigo objetiva discutir aspectos da vida produtiva e reprodutiva feminina, analisando a distribuição do tempo com afazeres domésticos e jornada de trabalho fora de casa, comparando trabalhadoras com filhos e sem filhos, de 16 a 59 anos de idade, residentes em áreas metropolitanas. As informações são provenientes das PNADs 2002 e 2012. Os resultados apontam para a manutenção de uma extensa jornada semanal feminina dedicada tanto ao trabalho doméstico-familiar quanto ao trabalho fora de casa. As mulheres ocupadas respondem por uma jornada média em afazeres domésticos três vezes superior à dos homens, principalmente as que são mães.
\end{abstract}

Palavras-chave: Trabalho feminino; Tarefas domésticas; Reprodução; Família; Desigualdade de gênero.

\section{Women's work-family time in Brazilian metropolitan areas}

Abstract: This article discusses the articulation between work and family life by analysis of the time that women spend on household chores and weekly working hours. We compared information from IBGE's PNAD 2002 and 2012 for women who has children and childless, with 16-59 years old, living in metropolitan areas. The results showed that female workers spends extensive weekly hours to both the domestic-family chores and labour. The analysis also shows that female workers spend three times higher hours than male workers on household tasks, especially those who are mothers.

Keywords: Female work; Household tasks; Reproduction; Family, Gender inequalities

*Professora Livre Docente em Demografia - IFCH/Unicamp e Nepo/Unicamp. **Doutora em Demografia (IFCH/Unicamp), Pesquisadora do Núcleo de Estudos de População "Elza Berquó" (Nepo/Unicamp). Contato: gal@nepo. unicamp.br. Recebido em: 22/12/2015 - Aceito em: 25/04/2016. 
$|62|$

Os tempos para o trabalho e para a família...

Tiempo de trabajo y família entre mujeres de las áreas metropolitanas brasileñas

Resumen: El artículo tiene como objetivo discutir aspectos de la vida productiva y reproductiva femenina, analiza el tiempo dedicado a las tareas del hogar y el trabajo. El análisis se basa en datos de la Encuesta Nacional de Hogares 2002 y 2012 compara la información de las trabajadoras que son madres y las sin hijos, tienen 16-59 años de edad y viven en las áreas metropolitanas. Los resultados apuntan al mantenimiento de una extensa cantidad de horas dedicado al trabajo doméstico-familiar y el trabajo fuera del hogar. Las mujeres trabajadoras gastan tres veces más horas en el trabajo doméstico que los hombres, especialmente madres.

Palabra clave: Trabajo femenino; Tareas domésticas; Reproducción; Familia; Desigualdad de Género.

\section{Introdução}

A crescente incorporação da população feminina no mercado de trabalho a partir da década de 1970 resultou em uma mudança gradativa no perfil das trabalhadoras brasileiras, com um contingente cada vez mais expressivo de mulheres mais velhas, em união conjugal e com filhos. Questionamentos sobre as condições pelas quais a inserção laboral feminina se dá em nossa sociedade sempre estiveram presentes nos estudos sobre trabalho, mas esse debate tem sido ampliado e aprofundado na medida em que dimensões de gênero, classe e raça tornaram-se mais presentes nas análises, lançando luz sobre avanços, mas, principalmente, para as múltiplas desigualdades existentes e persistentes. (NEVES, 2013; BRUSCHINI, RICOLDI, 2008; BRUSCHINI, 2007; BRUSCHINI, LOMBARDI, 2001; BRUSCHINI, 2000). Um deles é que muito embora tenha se ampliado a inserção e permanência das mulheres no mercado de trabalho, evidências tem mostrado que isso não tem amenizado ou modificado a carga de responsabilidades femininas com a vida doméstica-familiar.

Estudos que se debruçam sobre a conjugação da vida familiar e laboral feminina no Brasil apontam que a inserção da mulher no mercado de trabalho não se reflete em jornadas menos intensas no âmbito doméstico. Nem mesmo para aquelas que podem delegar responsabilidades para outras pessoas, que 
geralmente são outras mulheres, persiste a expectativa de que o gerenciamento da vida privada - cuidados com a casa e para com outros membros familiares - seja assumido pelas mulheres, invariavelmente as esposas/companheiras e mães. O que significa para a vida das mulheres a repartição dos dias em duas e até três jornadas de trabalho (CASTRO, 2012; BRUSCHINI, RICOLDI, 2008; BRUSCHINI, RICOLDI, 2009; BRUSCHINI, 2007; HIRATA e KERGOAT, 2007; DEDECCA, 2004).

Autoras como Hirata e Kergoat (2007) questionam conceitualmente a consideração dessa conjugação como "conciliação" e até mesmo "articulação", na medida em que contemplaria uma concepção de complementaridade ou harmonização de uma divisão sexual do trabalho, que é essencialmente assimétrica. Trata-se, como enfatizam as autoras, de contextos de vida femininos permeados por desigualdades, que geram mais conflitos, tensões e contradições do que conciliações.

As reflexões contidas nesse artigo se pautam por esse debate, procurando analisar o perfil das mulheres que trabalham e cuidam das responsabilidades domésticas, comparando dois períodos 2002 e 2012 - a partir de dados coletados pelo IBGE na Pesquisa Nacional por Amostra de Domicílios (PNAD). As informações consideradas dizem respeito ao trabalho, composição familiar e tempo dedicado em afazeres domésticos ${ }^{1}$ da população feminina e masculina, entre 16 e 59 anos de idade, residente nas principais regiões metropolitanas do país.

\footnotetext{
${ }^{1} \mathrm{Na}$ PNAD, entende-se por afazeres domésticos a realização de tarefas de: arrumar ou limpar toda ou parte da moradia; cozinhar, passar roupa, lavar roupa ou louça; orientar ou dirigir trabalhadores domésticos na execução das tarefas domésticas; cuidar de filhos ou menores moradores ou limpar o quintal ou terreno que circunda a residência. (Informação contida nas Notas Metodológicas da PNAD).
} 
$|64|$

Os tempos para o trabalho e para a família...

\section{Fontes e métodos}

As informações analisadas são da Pesquisa Nacional por Amostra de Domicílios (PNAD), realizadas para o ano de 2002 e 2012, explorando características da população de 16 a 59 anos de idade, tais como: condição de atividade, ocupação e jornada semanal de trabalho; assim como informações familiares referentes à posição no domicílio, status reprodutivo, número de filhos tidos; a existência de filha(o)s residentes no domicílio ${ }^{2}$ e tempo dedicado à realização de tarefas domésticas.

A delimitação da população na faixa de 16 a 59 anos de idade, permite, acreditamos, uma análise mais acurada das mulheres que majoritariamente estariam sujeitas de forma mais intensa às demandas concomitantes da vida profissional e familiar e seus conflitos e contradições. O recorte geográfico considerando as Regiões Metropolitanas de Belém, Fortaleza, Recife, Salvador, Belo Horizonte, Rio de Janeiro, São Paulo, Curitiba e Porto Alegre, procura refletir sobre a questão da articulação entre a vida produtiva e reprodutiva em diferentes contextos, tendo em vista que as desigualdades regionais ainda são marcantes em nosso país.

Trata-se de uma abordagem quantitativa, baseada em análises descritivas e na aplicação de um modelo de regressão logística ${ }^{3}$, visando aprofundar na reflexão sobre as características e condições em que se dão a articulação da vida produtiva e reprodutiva das mulheres brasileiras contemporâneas.

2 Todos os dados referentes aos filhos dizem respeito exclusivamente à população feminina, na medida em que não são captadas informações semelhantes sobre filhos tidos pelos homens.

${ }^{3}$ Agradecemos em especial a bolsista de Iniciação Científica Renata Cavinato Cornea (PIBIC 2014-2015) cujo trabalho foi fundamental para a realização das análises descritas e dos modelos de regressão. 


\section{Os tempos para o trabalho e para a família}

A parcela crescente de mulheres brasileiras que se coloca no mercado de trabalho desde a década de 1970 tem sido documentada por vários estudos. (BRUSCHINI, RICOLDI, 2008; BRUSCHINI, 2007; BRUSCHINI, LOMBARDI, 2001; BRUSCHINI, 2000) Em pesquisa recente, comparando as séries de dados dos Censos Brasileiros, Guimarães, Barone e Brito (2015) mostram que a taxa de participação feminina cresceu quase quatro vezes em um período de 50 anos. Em 1960, a PEA feminina era de 17\%, atingindo os 53\% em 2010.

Dados referentes à década mais recente, extraídas da PNAD e considerando a população entre 16 a 59 anos de idade, mostram que a PEA feminina oscilou em torno dos 55\% para o Brasil, apresentando taxas de participação mais elevadas nas principais Regiões Metropolitanas (RMs). Na Tabela 1, abaixo, destaca-se que a PEA feminina nas RMs estava acima dos 58\% já em 2002, exibindo incremento relativo em 2012, para todas as áreas. Destaque para Belo Horizonte, Curitiba e Fortaleza. A taxa de participação masculina permanece elevada, mas, diferente do observado para as mulheres, sua variação foi de ligeiro decréscimo na maioria das RMs, em particular, Porto Alegre e Rio de Janeiro.

Ter filhos parece ainda restringir a participação das mulheres no mercado de trabalho. Exceto para a Grande Belém, todas as demais RMs apresentam taxas de participação maiores para as mulheres sem filhos. Entre os anos destacados, a diferença observada entre aquelas com filhos e as sem filhos diminuiu, sendo a Grande São Paulo a única RM a registrar uma diferença de mais de 10 p.p. favorável para a participação das mulheres sem filhos. No caso da RM de Belém, a participação das mulheres com filhos se manteve mais elevada em torno de 4 p.p.. A redução das diferenças é resultado do maior incremento relativo da participação das mulheres mães, entre os anos destacados, em quase todas as RMs. (Tabela 1). 
Os tempos para o trabalho e para a família...

\section{TABELA 1 - Condição de participação e ocupação da população} de 16 a 59 anos de idade. Regiões Metropolitanas, 2002 e 2012

\begin{tabular}{|c|c|c|c|c|c|c|}
\hline & $\begin{array}{c}\text { Taxa de } \\
\text { participação } \\
\text { masculina (\%) }\end{array}$ & $\begin{array}{c}\text { Taxa de } \\
\text { participação } \\
\text { feminina } \\
(\%)\end{array}$ & $\begin{array}{c}\text { Taxa de } \\
\text { participação } \\
\text { das mulheres } \\
\text { com filhos } \\
(\%)\end{array}$ & $\begin{array}{c}\text { Taxa de } \\
\text { participação } \\
\text { das mulheres } \\
\text { sem filhos } \\
(\%)\end{array}$ & $\begin{array}{c}\% \text { de } \\
\text { mulheres } \\
\text { na } \\
\text { população } \\
\text { ocupada }\end{array}$ & $\begin{array}{c}\text { \% com } \\
\text { filhos na } \\
\text { população } \\
\text { feminina } \\
\text { ocupada }\end{array}$ \\
\hline \multicolumn{7}{|l|}{2002} \\
\hline Belém & 83,4 & 61,5 & 62,9 & 58,2 & 43,3 & 73,1 \\
\hline Fortaleza & 85,6 & 62,9 & 60,7 & 67,5 & 45,0 & 67,6 \\
\hline Recife & 83,7 & 59,0 & 56,6 & 64,7 & 43,3 & 68,2 \\
\hline Salvador & 88,0 & 71,1 & 70,3 & 72,6 & 45,5 & 67,5 \\
\hline $\begin{array}{c}\text { Belo } \\
\text { Horizonte }\end{array}$ & 88,0 & 68,1 & 64,2 & 75,2 & 44,5 & 63,1 \\
\hline $\begin{array}{l}\text { Rio de } \\
\text { Janeiro }\end{array}$ & 86,4 & 60,7 & 57,4 & 67,9 & 42,9 & 66,5 \\
\hline São Paulo & 89,6 & 66,6 & 60,9 & 78,3 & 43,5 & 62,2 \\
\hline Curitiba & 90,6 & 67,3 & 63,0 & 77,0 & 43,9 & 65,4 \\
\hline $\begin{array}{l}\text { Porto } \\
\text { Alegre }\end{array}$ & 90,0 & 69,6 & 67,3 & 74,8 & 43,9 & 69,3 \\
\hline \multicolumn{7}{|l|}{2012} \\
\hline Belém & 84,9 & 63,5 & 64,8 & 60,3 & 43,4 & 73,1 \\
\hline Fortaleza & 85,4 & 66,0 & 64,5 & 68,9 & 44,9 & 66,1 \\
\hline Recife & 85,1 & 60,9 & 59,5 & 63,5 & 43,2 & 66,7 \\
\hline Salvador & 88,2 & 71,6 & 71,2 & 72,4 & 46,2 & 66,7 \\
\hline $\begin{array}{c}\text { Belo } \\
\text { Horizonte }\end{array}$ & 89,0 & 74,6 & 71,6 & 80,1 & 46,7 & 63,3 \\
\hline $\begin{array}{l}\text { Rio de } \\
\text { Janeiro }\end{array}$ & 84,8 & 62,4 & 61,8 & 63,9 & 44,1 & 67,7 \\
\hline São Paulo & 89,0 & 69,3 & 64,8 & 77,6 & 45,6 & 60,9 \\
\hline Curitiba & 89,9 & 71,9 & 69,3 & 77,1 & 45,1 & 66,0 \\
\hline $\begin{array}{l}\text { Porto } \\
\text { Alegre }\end{array}$ & 87,4 & 72,3 & 71,1 & 74,6 & 46,5 & 65,1 \\
\hline
\end{tabular}

Fonte: IBGE, PNAD 2002 e 2012. 
No total dos trabalhadores ocupados, as mulheres constituem mais de $40 \%$ da força de trabalho em todas as RMs e cerca de $2 / 3$ delas tinham filhos (Tabela 1). A taxa de desocupação feminina (dados não mostrados aqui) nas RMs apresentou redução de um ano para o outro. Nas RMs do Sul e Sudeste, a desocupação feminina em 2012 estava abaixo dos 10\%, enquanto no Norte e Nordeste o nível máximo registrado foi de $16 \%$. Diferente do que se observou para a condição de atividade, esse indicador se mostra mais desfavorável para as mulheres sem filhos. Em 2012, o desemprego nesse segmento feminino variou de $8 \%$ a $20 \%$ nas RMs. Enquanto entre as mulheres mães essa variação foi de $4 \%$ a $14 \%$. Em certa medida, a maior desocupação entre as mulheres sem filhos pode ser explicada pelo fato desse segmento abrigar uma parcela significativa de mulheres ainda bem jovens e que justamente são aquelas que encontram maior dificuldade de se inserir (primeiro emprego) e se manter no mercado de trabalho.

A distribuição da população feminina ocupada segundo sua jornada de trabalho fora de casa também sofreu alterações expressivas. O peso relativo das mulheres que trabalham jornadas a partir de 40 semanais teve incrementos em todas as RMs, conforme é ilustrado pelos Gráficos 1 e 2, a seguir. 
|68|

Os tempos para o trabalho e para a família...

Gráfico 1: Distribuição (\%) da população feminina de 16 a 59 anos, ocupada, sem filhos segundo jornada de trabalho. Regiões Metropolitanas 2002 e 2012

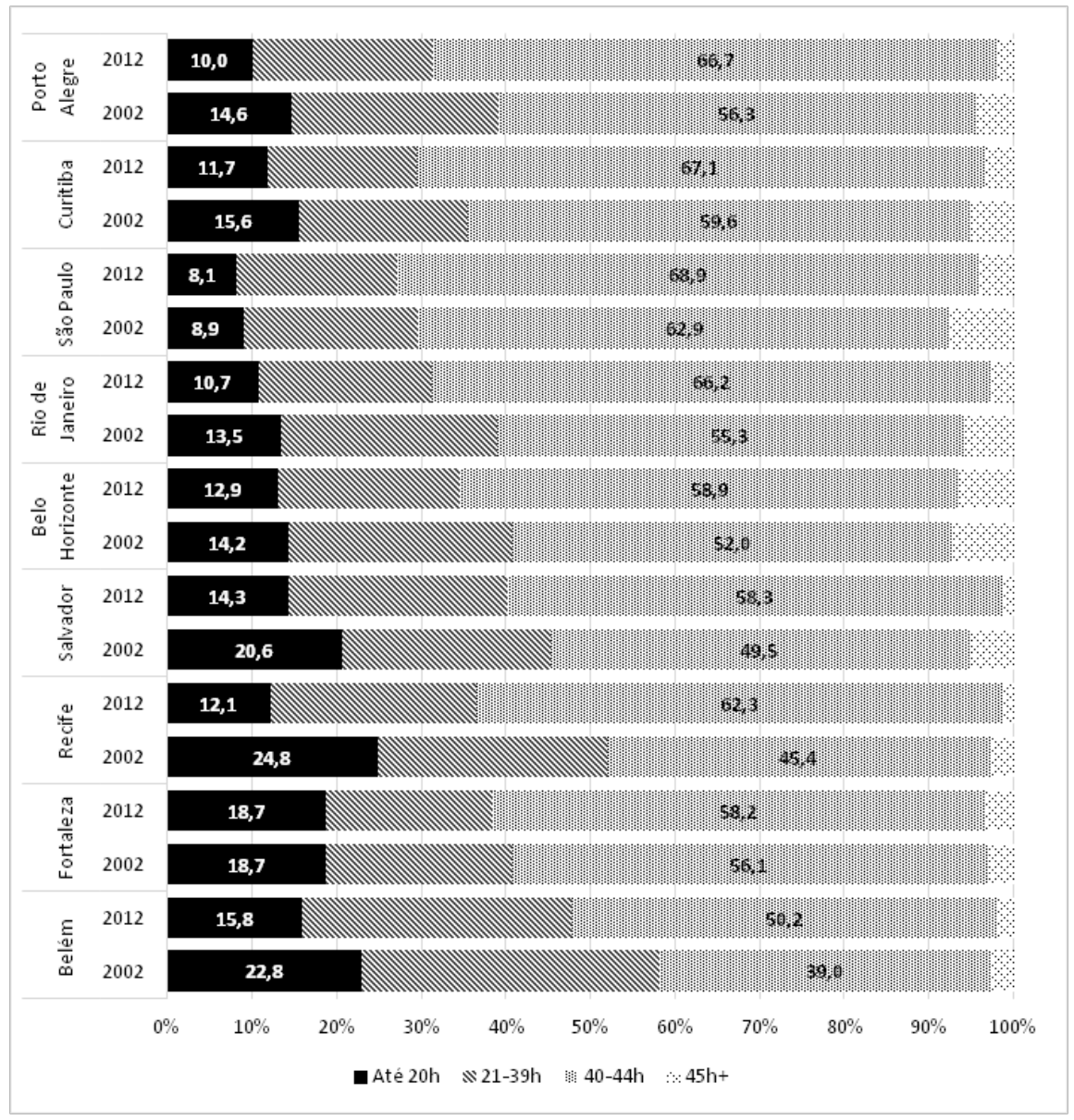

Fonte: IBGE, PNAD 2002 e 2012. 
Nota-se que entre as mulheres sem filhos, em 2012, nenhuma RM registrou menos da metade delas em jornadas abaixo de 40 horas semanais. No Sul e Sudeste, elas representam 2/3 desse segmento feminino. (Gráfico 1)

No segmento de mulheres com filhos e ocupadas, os resultados se assemelham ao descrito acima. Mas é importante destacar que o aumento do peso relativo daquelas em trabalhos com jornadas de 40 horas ou mais por semana foi maior ao observado para aquelas sem filhos, porém, esse segmento continua com proporções maiores de mulheres em jornadas de até 20 horas semanais. Outro ponto que se destaca é que nesse grupo de mulheres, a Grande Belém representa uma exceção. Trata-se da única RM em que a maioria das mulheres mães que trabalhavam ainda estavam em jornadas inferiores a 40 horas semanais (Gráfico 2). 
$|70|$

Os tempos para o trabalho e para a família...

Gráfico 2: Distribuição (\%) da população feminina de 16 a 59 anos, ocupada, com filhos segundo jornada de trabalho. Regiões Metropolitanas 2002 e 2012

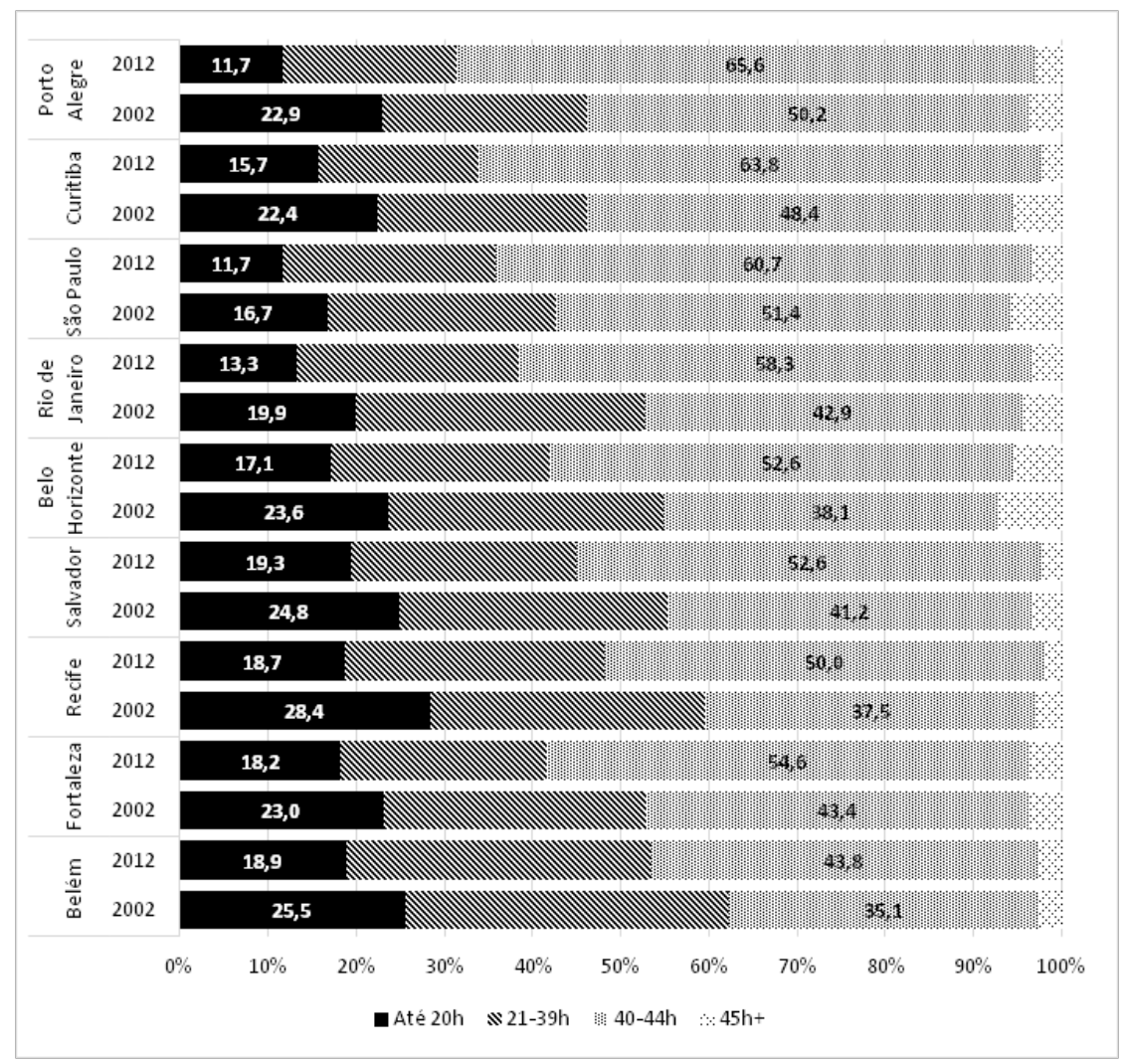

Fonte: IBGE, PNAD 2002 e 2012.

Tenham filhos ou não, a população feminina de 16 a 59 anos em maiores proporções tem disponibilizado sua mão de obra no mercado de trabalho, tem igualmente conseguido se empregar e em ocupações em jornadas full time (40 horas ou mais). O que nos 
levaria a pensar se esta mudança teria de alguma forma afetado as características ou os tempos do trabalho voltado para o cuidado da família e do espaço doméstico. Os dados a seguir indicam que muito pouco se modificou.

Pode-se ver pelo Gráfico 3 que a proporção de mulheres que declarou ter realizado algum afazer doméstico é expressivamente maior que a proporção de homens em todas as RMs. Enquanto quase que a totalidade das mulheres de 16 a 59 anos declarou ter realizado algum tipo de afazer doméstico durante a semana, a proporção de homens nessa faixa etária que declarou ter feito o mesmo variou de $35 \%$ a $67 \%$ nos anos destacados.

Nota-se algumas diferenças na declaração masculina entre as RMs. Salvador, Belo Horizonte e Porto Alegre registram as maiores proporções de declaração masculina - acima de 60\% em 2012 - enquanto Rio de Janeiro apresenta a menor parcela de homens que realizam afazeres domésticos - abaixo dos $40 \%$ nos dois períodos em destaque (Gráfico 3). 
GRÁFICO 3 - Proporção da população de 16 a 59 anos de idade que declarou ter realizado algum afazer doméstico na semana de referência por sexo. Regiões Metropolitanas, 2002 e 2012

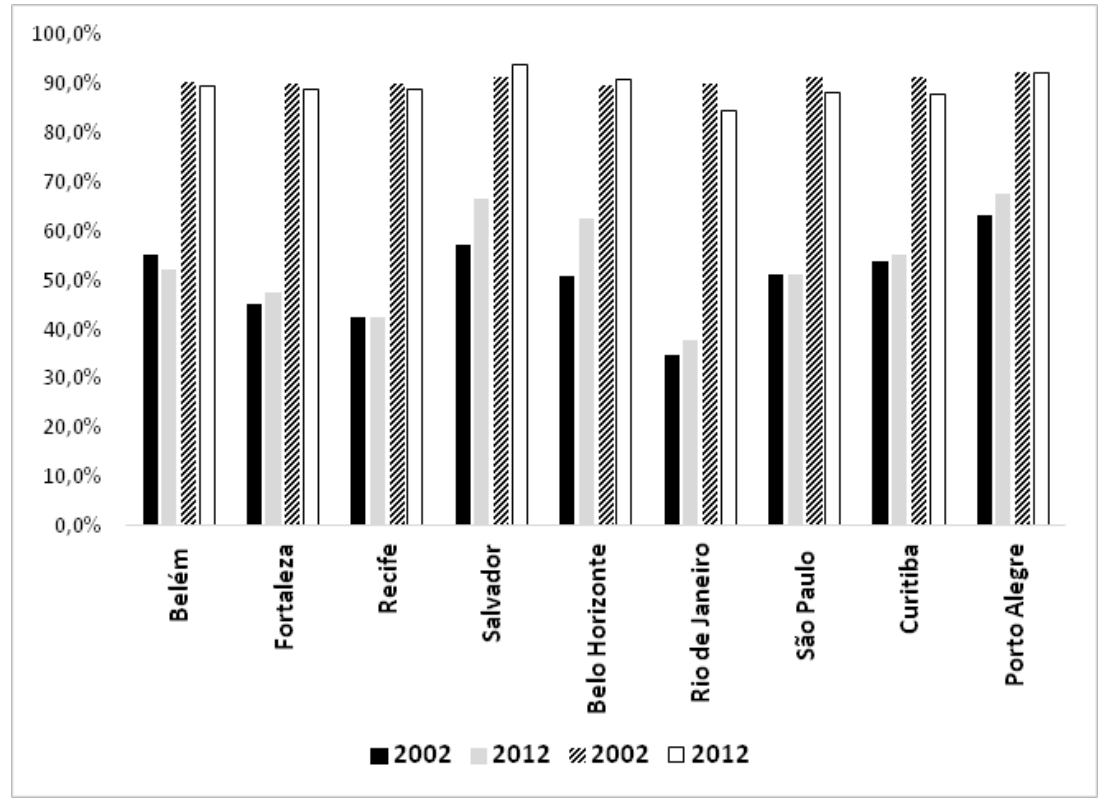

Fonte: IBGE, PNAD 2002 e 2012. Tabulações próprias.

As informações do Gráfico 3 não chegam a surpreender diante de uma quantidade expressiva de estudos que apontam para a persistência de um contemporâneo padrão desigual de divisão sexual do trabalho, no qual se intensificam as atribuições femininas com a articulação da esfera produtiva e reprodutiva, e as atribuições masculinas majoritariamente ainda se resumem ao trabalho e ao provimento financeiro. Conclusões que frustram em grande medida as expectativas de que o trabalho remunerado feminino e, consequentemente, a sua maior contribuição no orçamento doméstico-familiar pudessem aumentar o poder de barganha das mulheres, e dessa forma, reduzir as desigualdades 
de gênero (WAJNMAN, 2012; GUEDES, 2010; SORJ, FONTES, MACHADO, 2007; BRUSCHINI, 2007; OLIVEIRA, 2007; OLIVEIRA e MARCONDES, 2004; HIRATA, 2004; MONTALI, 2004; BRUSCHINI, LOMBARDI, 2001).

Dados mais recentes reiteram a percepção de uma desigualdade persistente. Quando se avalia a articulação entre a jornada de trabalho no mercado e no espaço doméstico, pode-se observar pela Tabela 2 que a média de horas dedicada em afazeres domésticos pela população masculina pouco se altera conforme a sua jornada de trabalho nos dois anos em destaque, diferente do tempo médio da população feminina, que diminui expressivamente quando a jornada de trabalho é maior, particularmente para as mulheres com filhos.

TABELA 2 - Horas médias com afazeres domésticos na população ocupada de 16 a 59 anos, por sexo, status reprodutivo das mulheres e jornada de trabalho. Regiões Metropolitanas, 2002 e 2012

\begin{tabular}{c|c|c|c|c|c|c}
\hline \multirow{2}{*}{$\begin{array}{c}\text { RM/ } \\
\text { Jornada de } \\
\text { trabalho }\end{array}$} & Homens & $\begin{array}{c}\text { Mulheres } \\
\text { sem filhos }\end{array}$ & $\begin{array}{c}\text { Mulheres } \\
\text { com filhos }\end{array}$ & Homens & $\begin{array}{c}\text { Mulheres } \\
\text { sem filhos }\end{array}$ & $\begin{array}{c}\text { Mulheres } \\
\text { com filhos }\end{array}$ \\
\cline { 2 - 7 } $\begin{array}{c}\text { Até 20 } \\
\text { horas }\end{array}$ & & & & & \\
Belém & 10,5 & 14,2 & 27,8 & 13,9 & 17,1 & 27,8 \\
$\begin{array}{c}\text { Fortaleza } \\
\text { Recife }\end{array}$ & 12,5 & 17,9 & 38,4 & 12,2 & 15,8 & 33,1 \\
Salvador & 11,3 & 18,4 & 34,8 & 14,1 & 18,6 & 31,7 \\
Belo & 12,9 & 16,7 & 31,0 & 11,4 & 18,0 & 27,9 \\
Horizonte & 12,3 & 17,3 & 34,7 & 9,1 & 13,8 & 33,4 \\
Rio de & 11,3 & 16,7 & 30,2 & 11,9 & 16,2 & 25,7 \\
$\begin{array}{c}\text { Janeiro } \\
\text { São Paulo }\end{array}$ & 11,6 & 19,6 & 34,4 & 9,7 & 16,6 & 25,6 \\
Curitiba & 11,2 & 20,0 & 36,8 & 7,9 & 12,2 & 31,4 \\
Porto & 12,2 & 17,5 & 35,0 & 11,7 & 13,5 & 28,0 \\
Alegre & 12 & & & &
\end{tabular}


Os tempos para o trabalho e para a família...

\begin{tabular}{|c|c|c|c|c|c|c|}
\hline $\begin{array}{l}40-44 \\
\text { horas }\end{array}$ & & & & & & \\
\hline Belém & 8,4 & 13,9 & 16,8 & 10,7 & 14,8 & 19,3 \\
\hline Fortaleza & 11,7 & 15,6 & 21,3 & 11,5 & 16,2 & 22,4 \\
\hline Recife & 10,0 & 15,4 & 20,1 & 11,5 & 18,1 & 22,6 \\
\hline Salvador & 9,9 & 13,1 & 19,3 & 10,0 & 15,8 & 20,0 \\
\hline $\begin{array}{c}\text { Belo } \\
\text { Horizonte }\end{array}$ & 9,1 & 13,0 & 20,1 & 9,0 & 12,6 & 21,4 \\
\hline $\begin{array}{l}\text { Rio de } \\
\text { Janeiro }\end{array}$ & 10,3 & 16,2 & 20,8 & 9,9 & 13,9 & 19,2 \\
\hline São Paulo & 8,7 & 13,6 & 22,0 & 9,6 & 12,7 & 18,1 \\
\hline Curitiba & 7,4 & 12,8 & 19,9 & 8,4 & 12,1 & 18,7 \\
\hline $\begin{array}{l}\text { Porto } \\
\text { Alegre }\end{array}$ & 10,4 & 13,3 & 21,7 & 9,9 & 13,2 & 20,7 \\
\hline
\end{tabular}

Fonte: IBGE, PNAD 2002 e 2012.

Entre os homens observa-se que há poucas diferenças entre as médias de horas dispendidas com afazeres domésticos entre aqueles que trabalham 20 horas e 40-44 horas semanais. Em 2002, a variação entre as médias foi de 1 hora (Fortaleza, Salvador e Rio de Janeiro, por exemplo) até 4 horas (Curitiba) a mais para aqueles que trabalhavam até 20 horas semanais. No ano de 2012, essa variação foi de menos de 1 hora (Fortaleza, Belo Horizonte e São Paulo) até 3 horas (Belém). Essa redução na diferença acontece de forma semelhante entre as médias das mulheres sem filhos. $\mathrm{O}$ maior diferencial encontra-se, de fato, nas horas médias das mulheres com filhos. No ano de 2002, a variação entre as médias foi de 9 horas (Rio de Janeiro) até 17 horas (Fortaleza) a mais para aquelas que trabalhavam até 20 horas semanais. Em 2012, essa variação caiu para 6 horas (Rio de Janeiro) até 12 horas (Belo Horizonte e Curitiba). Ou seja, o tempo gasto com as tarefas domésticas tendem a ser mais próximas entre homens e mulheres, quando estas não têm filhos. Quando estas são mães os tempos com afazeres tende a ser maior, principalmente entre aquelas que trabalham fora de casa em jornadas de até 20 horas semanais. (Tabela 2) 
O tempo médio que homens e mulheres, que trabalham fora de casa, dispensam para a realização de tarefas domésticas também difere conforme sua posição dentro do domicílio. (Tabela 3)

TABELA 3 - Horas médias dispendidas com afazeres domésticos na população ocupada de 16 a 59 anos, por sexo e posição no domicílio. Regiões Metropolitanas, 2002 e 2012

\begin{tabular}{|c|c|c|c|c|c|c|c|c|}
\hline \multirow{2}{*}{$\begin{array}{c}\text { Regiões } \\
\text { tropolitanas }\end{array}$} & \multicolumn{4}{|c|}{ Homem } & \multicolumn{4}{|c|}{ Mulher } \\
\hline & $\begin{array}{l}\text { Pessoa de } \\
\text { referência }\end{array}$ & Cônjuge & Filho & $\begin{array}{c}\text { Outro } \\
\text { Parente }\end{array}$ & $\begin{array}{c}\text { Pessoa de } \\
\text { referência }\end{array}$ & Cônjuge & Filha & $\begin{array}{c}\text { Outra } \\
\text { Parente }\end{array}$ \\
\hline \multicolumn{9}{|l|}{2002} \\
\hline Belém & 9,0 & 8,8 & 8,6 & 8,9 & 20,2 & 21,7 & 13,6 & 14,5 \\
\hline Fortaleza & 12,0 & 16,4 & 11,4 & 11,2 & 24,3 & 27,6 & 16,5 & 17,3 \\
\hline Recife & 10,8 & 11,8 & 9,7 & 9,5 & 21,4 & 27,2 & 16,8 & 18,6 \\
\hline Salvador & 10,6 & 11,3 & 9,2 & 9,6 & 20,5 & 25,2 & 13,9 & 15,9 \\
\hline $\begin{array}{c}\text { Belo } \\
\text { Horizonte }\end{array}$ & 10,2 & 12,5 & 8,9 & 10,4 & 20,5 & 26,0 & 13,8 & 14,0 \\
\hline $\begin{array}{l}\text { Rio de } \\
\text { Janeiro }\end{array}$ & 11,1 & 7,5 & 8,8 & 9,2 & 20,5 & 24,6 & 15,5 & 17,9 \\
\hline São Paulo & 9,4 & 9,8 & 7,0 & 8,8 & 21,8 & 25,3 & 13,0 & 18,2 \\
\hline Curitiba & 8,6 & 9,8 & 7,5 & 9,0 & 20,2 & 24,1 & 13,3 & 15,1 \\
\hline $\begin{array}{c}\text { Porto } \\
\text { Alegre }\end{array}$ & 10,7 & 10,4 & 8,7 & 9,2 & 20,4 & 25,3 & 13,8 & 14,1 \\
\hline \multicolumn{9}{|l|}{2012} \\
\hline Belém & 12,6 & 11,0 & 10,2 & 9,6 & 21,2 & 23,2 & 16,2 & 17,0 \\
\hline Fortaleza & 12,6 & 11,8 & 9,0 & 9,7 & 24,0 & 25,6 & 16,3 & 15,7 \\
\hline Recife & 13,2 & 10,3 & 12,0 & 12,2 & 24,6 & 25,6 & 18,3 & 19,6 \\
\hline Salvador & 10,9 & 10,6 & 8,5 & 8,9 & 21,0 & 23,9 & 13,8 & 15,1 \\
\hline $\begin{array}{c}\text { Belo } \\
\text { Horizonte }\end{array}$ & 9,8 & 8,8 & 7,6 & 8,0 & 21,1 & 23,8 & 12,0 & 14,0 \\
\hline $\begin{array}{l}\text { Rio de } \\
\text { Janeiro }\end{array}$ & 11,0 & 9,9 & 9,7 & 9,5 & 20,2 & 21,4 & 13,8 & 15,6 \\
\hline São Paulo & 10,0 & 9,0 & 8,1 & 8,9 & 18,5 & 19,2 & 11,8 & 14,8 \\
\hline Curitiba & 8,8 & 9,2 & 6,9 & 7,6 & 18,4 & 21,4 & 11,5 & 11,9 \\
\hline $\begin{array}{c}\text { Porto } \\
\text { Alegre }\end{array}$ & 11,0 & 9,6 & 8,8 & 9,7 & 19,7 & 21,2 & 13,0 & 14,2 \\
\hline
\end{tabular}

Fonte: IBGE, PNAD 2002 e 2012. 
Entre os homens, o tempo médio apresenta pequenas variações nas diferentes posições ocupadas no domicílio. As maiores horas médias masculinas aparecem nas RMs do Norte e Nordeste. No caso das mulheres, as diferenças entre as posições são bem mais expressivas. Na Tabela 3, acima, é visível o quanto a posição de pessoa de referência e, principalmente, de cônjuge no domicílio representa para as mulheres o comprometimento do seu tempo com a realização de tarefas domésticas. E nas RMs do Norte e Nordeste, isso aparece de forma mais destacada. Chama atenção, na comparação entre os anos, que em algumas RMs as horas médias femininas com afazeres domésticos apresentou uma grande redução. Na Grande São Paulo, por exemplo, para as cônjuges esse decréscimo foi de cerca de 6 horas médias, enquanto para as mulheres responsáveis pelo domicílio, 4 horas em média. A Grande Curitiba também se destaca pela redução observada em todas as posições ocupadas pelas mulheres.

Na medida em que grande parte das responsáveis e cônjuges são mães, os tempos médios registrados são bem próximos aos observados para as mulheres ocupadas com filhos, conforme visto anteriormente. Esse conjunto de informações reforça os questionamentos sobre a acentuação de desigualdades de gênero. Parece muito plausível a reflexão de que a vida cotidiana feminina permanece predominantemente ocupada com serviços prestados a suas famílias. Mesmo entre aquelas que dividem seu tempo com o trabalho fora de casa, seus tempos médios com afazeres domésticos representam o acréscimo de uma segunda jornada de trabalho semanal de não menos que 17 horas. Aproximadamente equivalente ao que é considerado uma meia jornada semanal no mercado de trabalho. Isso significa que a jornada total semanal de uma parcela nada desprezível de mulheres ocupadas está acima de 60 horas de trabalho. Como alguns autores chamam atenção (WAJMANN, 2012; DEDECCA, 2004), semanalmente, as mulheres gastam muito mais horas trabalhando do que os homens.

Para aprofundar a análise foram elaborados, com auxílio do software estatístico R, modelos de regressão logística com o objetivo de avaliar os fatores mais associados a probabilidade das mulheres 
de 16 a 59 anos a dispender um tempo acima da média na realização de afazeres domésticos. Desse modo, dois modelos de regressão logística binomial foram construídos; um considerando apenas as mulheres que são mães e outro apenas as mulheres que trabalham. Replicados para os anos de 2002 e 2012. A variável resposta para ambos os modelos é dicotômica, assumindo o valor ' 0 ' para aquelas mulheres cujo tempo gasto com afazeres domésticos é até a hora média registrada para o segmento feminino em estudo e ' 1 ' para aquelas que estão acima da hora média.

Os modelos construídos relacionam um conjunto de variáveis com a variável resposta dicotômica (se está ou não acima da média) $)^{4}$. Os resultados serão apresentados na forma dos níveis de significância das variáveis, suas razões de chances ${ }^{5}$ e os intervalos de confiança das razões de chances.

\section{O tempo com os afazeres domésticos das mulheres mães}

Na aplicação do modelo logístico binário, os resultados na Tabela 4 mostram que apenas as variáveis Cor e Região apresentam categorias com $p$-valor $>0,05$. O que significa que as associações não teriam significância estatística, considerando intervalo de confiança de $95 \%$. Por exemplo, dentre as mulheres de 16 a 59 anos

\footnotetext{
${ }^{4} \mathrm{E}(\mathrm{Y})=\pi(\mathrm{x})$ representa a probabilidade de ocorrência do evento, no nosso caso, a probabilidade de uma mulher ter um tempo acima da média na realização de tarefas domésticas. $\mathrm{O}$ modelo de regressão logística é dado pelo $\log (\pi(\mathrm{x}) /(1-\pi(\mathrm{x})))=\beta_{0}+\beta_{1} \mathrm{x}_{1}+\beta_{2} \mathrm{x}_{2}+\ldots \ldots .+\beta_{\mathrm{p}} \mathrm{x}_{\mathrm{p}^{\prime}}$ então, $\pi(\mathrm{x})=\exp \left(\beta_{0}+\beta_{1} \mathrm{x}_{1}+\beta_{2}\right.$ $\left.\mathrm{x}_{2}+\ldots \ldots+\beta_{\mathrm{p}} \mathrm{x}_{\mathrm{p}}\right) /\left(1+\exp \left(\beta_{0}+\beta_{1} \mathrm{x}_{1}+\beta_{2} \mathrm{x}_{2}+\ldots \ldots+\beta_{\mathrm{p}} \mathrm{x}_{\mathrm{p}}\right)\right)$

${ }^{5}$ Razão de Chances (Odds Ratio em inglês) é definida como a razão entre a chance de um evento ocorrer em um grupo em relação a chance de ocorrer em um outro grupo adotado como referência. Uma razão de chances igual a 1 indica que o evento sob estudo é igualmente provável de ocorrer nos dois grupos. Uma razão de chances maior que 1 indica que o evento tem maior probabilidade de ocorrer em relação ao grupo de referência. Uma razão de chances menor do que 1 indica que a probabilidade de ocorrência é menor em relação ao grupo de referência.
}

Idéias - Rev. Inst. Filos. Ciênc. Hum. UNICAMP, v.7, n.1, p. 61-88, jan/jul. 2016 
que tem filhos, em 2002, as que residem nas regiões metropolitanas de Fortaleza, Recife, Salvador, Belo Horizonte e Porto Alegre apresentaram resultados que não foram significativos, ao nível de significância de 5\% em relação às que residem na Grande São Paulo.

Entre aquelas RMs que apresentaram significância estatística, a informação de Odds Ratio, a Razão de Chance, nos diz sobre a magnitude dessas associações. Nas RMs de Belém, Rio de Janeiro e Curitiba as mulheres mães têm menos chances de apresentarem tempo acima da média em afazeres domésticos em relação àquelas mulheres mães que residem na RM de São Paulo (Tabela 4). Em 2012, os dados revelam uma situação oposta a 2002, todas as RMs apresentam significância estatística, ao nível de 5\%, e todas as regiões relevam chances maiores das mulheres de 16 a 59 anos com filhos dedicarem tempo acima da média em afazeres domésticos em relação aquelas que residem na Grande São Paulo, destacando as mulheres que residentes na RM de Fortaleza, que têm 3 vezes mais chance de dedicar tempo acima da média em afazeres domésticos que as mulheres residentes na Grande São Paulo. (Tabela 4) 


\section{TABELA 4 - Razão de Chance para fatores associados ao tempo} gasto acima da média com tarefas domésticas para a população feminina de 16 a 59 anos que tem filhos, 2002 e 2012

\begin{tabular}{|c|c|c|c|c|c|c|}
\hline & \multicolumn{3}{|c|}{2002} & \multicolumn{3}{|c|}{2012} \\
\hline & p-valor & $\begin{array}{c}\text { OR } \\
\text { (Razão } \\
\text { de } \\
\text { Chance) }\end{array}$ & $\begin{array}{c}\text { Intervalo } \\
\text { de } \\
\text { Confiança } \\
(95 \%)\end{array}$ & p-valor & $\begin{array}{c}\text { OR } \\
\text { (Razão } \\
\text { de } \\
\text { Chance) }\end{array}$ & $\begin{array}{c}\text { Intervalo de } \\
\text { Confiança } \\
\text { (95\%) }\end{array}$ \\
\hline (Intercepto) & $0,000^{* * * *}$ & & & $0,000^{* * *}$ & & 0,$99 ; 1,00$ \\
\hline Idade & $0,000^{* * *}$ & 1,01 & 1,$005 ; 1,013$ & 0,913 & 1 & \\
\hline Anos de estudo & & & & & & \\
\hline $0-7$ anos & & 1,00 & & & 1 & \\
\hline $8-11$ anos & $0,000^{* * *}$ & 0,86 & 0,$81 ; 0,93$ & $0,000^{* * *}$ & 0,79 & 0,$73 ; 0,85$ \\
\hline $12-14$ anos & $0,000^{* * * *}$ & 0,60 & 0,$48 ; 0,73$ & $0,000^{* * * *}$ & 0,74 & 0,$64 ; 0,85$ \\
\hline $15+$ anos & $0,000^{* * *}$ & 0,32 & 0,$27 ; 0,38$ & $0,000^{* * *}$ & 0,45 & 0,$40 ; 0,50$ \\
\hline Condição de ocupaçãa & & & & & & \\
\hline Ocupada & & 1 & & & 1 & \\
\hline Desocupada & $0,000^{* * * *}$ & 4,31 & 3,$92 ; 4,74$ & $0,000^{* * *}$ & 3,53 & 3,$15 ; 3,96$ \\
\hline Cor & & & & & & \\
\hline Brancas & & 1 & & & 1 & \\
\hline Negras & 0,621 & 1,02 & 0,$94 ; 1,1$ & $0,002^{* * *}$ & 1,04 & 1,$04 ; 1,21$ \\
\hline Outras & 0,161 & 1,29 & 0,$90 ; 1,86$ & 0,440 & 0,57 & 0,$57 ; 1,27$ \\
\hline Condição no domicíli & & & & & & \\
\hline Pessoa Responsável & & 1 & & & 1 & \\
\hline Cônjuge & $0,000^{* * * *}$ & 1,77 & 1,$63 ; 1,93$ & $0,000^{* * * *}$ & 1,27 & 1,$18 ; 1,36$ \\
\hline Filha & $0,000^{* * * *}$ & 0,61 & 0,$52 ; 0,71$ & $0,000^{* * *}$ & 0,45 & 0,$39 ; 0,52$ \\
\hline Outra & $0,007^{* * * *}$ & 0,74 & 0,$61 ; 0,92$ & $0,000^{* * *}$ & 0,59 & 0,$49 ; 0,72$ \\
\hline RM & & & & & & \\
\hline São Paulo & & 1 & & & 1 & \\
\hline Belém & $0,000^{* * * *}$ & 0,55 & 0,$47 ; 0,65$ & $0,000^{* * *}$ & 1,84 & 1,$59 ; 2,13$ \\
\hline Fortaleza & 0,054 & 1,14 & 0,$99 ; 1,31$ & $0,000^{* * *}$ & 3,11 & 2,$69 ; 3,59$ \\
\hline Recife & 0,474 & 1,05 & 0,$91 ; 1,2$ & $0,000^{* * *}$ & 2,51 & 2,$19 ; 2,88$ \\
\hline Salvador & 0,263 & 0,92 & 0,$81 ; 1,05$ & $0,000^{* * *}$ & 1,74 & 1,$52 ; 2,00$ \\
\hline Belo Horizonte & 0,688 & 0,97 & 0,$84 ; 1,12$ & $0,000^{* * *}$ & 2,03 & 1,$78 ; 2,33$ \\
\hline Rio de Janeiro & $0,000^{* * *}$ & 0,71 & 0,$62 ; 0,81$ & $0,000^{* * *}$ & 1,52 & 1,$33 ; 1,74$ \\
\hline Curitiba & $0,005^{* * *}$ & 0,78 & 0,$66 ; 0,93$ & $0,000^{* * *}$ & 1,41 & 1,$19 ; 1,67$ \\
\hline Porto Alegre & 0,059 & 0,88 & 0,$78 ; 1,00$ & $0,000^{* * *}$ & 1,56 & 1,$37 ; 1,78$ \\
\hline
\end{tabular}

Níveis de significância: ${ }^{* * *} \mathrm{p}$-valor $<0.001$; ${ }^{* *} \mathrm{p}$-valor $<0.01 ;{ }^{*} \mathrm{p}$-valor $<0.05$. 
$|80|$

Os tempos para o trabalho e para a família...

Nota-se igualmente que quanto maior a escolaridade das mulheres mães menores são as chances de apresentarem um tempo com afazeres domésticos acima da média registrada para esse segmento feminino. Para o grupo com 15 anos ou mais de escolaridade, por exemplo, em 2002, elas tinham 68\% menos de chance de estar acima da média do que as mulheres com até 7 anos de estudo. Em 2012, tinham 55\% a menos.

As mulheres com filhos e que não trabalhavam em 2002 tinham quatro vezes mais chances de apresentar tempo acima da média em afazeres domésticos que as mulheres com filhos que trabalhavam. Em 2012 essa chance diminuiu para três vezes.

Como destacado anteriormente, a posição ocupada pela mulher no domicílio tem forte associação com o tempo dispendido com afazeres domésticos. No resultado do modelo, as categorias se mostram estatisticamente significativas, ao nível de significância de $5 \%$, exceção à categoria "outra" em 2002. Nessa variável destacase que a mulher mãe que é cônjuge, em 2002, tinha $77 \%$ de chance de gastar um tempo acima da média com tarefas domésticas do que uma mulher mãe que é responsável pelo domicílio. Em 2012, a força dessa associação é reduzida para 27\%. Enquanto as mulheres mães e que são filhas da pessoa responsável pelo domicílio de 39\% a menos de chance de gastarem um tempo acima da média com afazeres domésticos em 2002, passam a ter 55\% a menos de chance em 2012.

No que se refere a idade, apenas o ano de 2002, apresenta significância estatística, com intervalo de confiança de $95 \%$, ou seja, quanto mais se avança na idade maior a chance de dedicar tempo acima da média em afazeres domésticos.

\section{O tempo com os afazeres domésticos das mulheres que trabalham}

No modelo a seguir em que são consideradas as mulheres de 16 a 59 anos que são ocupadas, novamente, a variável Cor foi a única que não apresentou significância estatística, com intervalo de confiança em $95 \%$. 
Para as demais variáveis, alguns dos resultados se assemelham ao encontrado para as mulheres mães. No que se refere às RMs, no ano de 2002, Belém, Salvador e Belo Horizonte foram as únicas áreas estatisticamente significantes ao nível de 5\%, todas com menores chances das mulheres ocupadas dispenderem um tempo acima da média com tarefas domésticas em relação aquelas residentes na Grande São Paulo. Em 2012, exceção feita as RMs do Rio de Janeiro e Curitiba, todas as demais exibiram maiores chances das mulheres ocuparem tempo acima da média comparadas as mulheres ocupadas e residentes em São Paulo (Tabela 5).

Nos dois anos analisados, as mulheres que trabalhavam e que não tinham filhos apresentaram 50\% menos chances de realizarem tarefas domésticas em um tempo acima da média do que aquelas que trabalham e tem filhos.

Assim como no modelo anterior, ser cônjuge representava, em 2002, 62\% a mais de chance para uma mulher ocupada de apresentar um tempo gasto acima da média com a realização de tarefas domésticas comparadas às responsáveis pelo domicílio. No ano de 2012, a chance era de $30 \%$ a mais. Para aquelas que ocupavam a posição de "Filhas", nos dois anos analisados, as chances de apresentarem um tempo acima da média era pouco mais de $50 \%$ a menos (Tabela 5). 
Os tempos para o trabalho e para a família...

TABELA 5 - Razão de Chance para fatores associados ao tempo gasto acima da média com tarefas domésticas para a população feminina de 16 a 59 anos que são ocupadas, 2002 e 2012

\begin{tabular}{|c|c|c|c|c|c|c|}
\hline & \multicolumn{3}{|c|}{2002} & \multicolumn{3}{|c|}{2012} \\
\hline & p-valor & $\begin{array}{c}\text { OR } \\
\text { (Razão } \\
\text { de } \\
\text { Chance) }\end{array}$ & $\begin{array}{c}\text { Intervalo } \\
\text { de } \\
\text { Confiança } \\
\text { (95\%) }\end{array}$ & p-valor & $\begin{array}{c}\text { OR } \\
\text { (Razão } \\
\text { de } \\
\text { Chance) }\end{array}$ & $\begin{array}{c}\text { Intervalo de } \\
\text { Confiança } \\
(95 \%)\end{array}$ \\
\hline (Intercepto) & $0,000^{* * * *}$ & & & $0,000^{* * *}$ & & \\
\hline $\begin{array}{c}\text { Idade } \\
\text { Anos de estudo }\end{array}$ & $0,000^{* * * *}$ & 1,01 & 1,$00 ; 1,01$ & $0,003^{* * * *}$ & 1 & 1,$00 ; 1,00$ \\
\hline $0-7$ anos & & 1 & & & 1 & \\
\hline $8-11$ anos & $0,001^{* * *}$ & 0,87 & 0,$80 ; 0,94$ & $0,000^{* * *}$ & 0,84 & 0,$77 ; 0,91$ \\
\hline $12-14$ anos & $0,000^{* * *}$ & 0,46 & 0,$39 ; 0,55$ & $0,000^{* * * *}$ & 0,61 & 0,$53 ; 0,7$ \\
\hline $\begin{array}{l}\text { 15+ anos } \\
\text { Jornada de Trabalho }\end{array}$ & $0,000^{* * *}$ & 0,35 & 0,$31 ; 0,40$ & $0,000^{* * *}$ & 0,43 & 0,$39 ; 0,49$ \\
\hline Até 20 horas & $0,000^{* * *}$ & 3,39 & 3,$08 ; 3,73$ & $0,000^{* * *}$ & 2,28 & 2,$07 ; 2,51$ \\
\hline $\begin{array}{l}\text { de } 21 \text { horas a } 39 \text { oras } \\
\text { de } 40 \text { horas a } 44 \text { horas }\end{array}$ & $0,000^{* * *}$ & $\begin{array}{c}2,18 \\
1\end{array}$ & 1,$99 ; 2,37$ & $0,000^{* * * *}$ & $\begin{array}{c}1,67 \\
1\end{array}$ & 1,$55 ; 1,81$ \\
\hline $\begin{array}{c}45 \text { horas e mais } \\
\text { Cor }\end{array}$ & 0,258 & 0,89 & 0,$74 ; 1,08$ & 0,300 & 1,10 & 0,$91 ; 1,33$ \\
\hline Brancas & & 1 & & & 1 & \\
\hline Negras & 0,095 & 1,07 & 0,$98 ; 1,16$ & $0,002^{* * *}$ & 1,12 & 1,$04 ; 1,21$ \\
\hline Outras & 0,428 & 1,16 & 0,$79 ; 1,69$ & 0,850 & 0,96 & 0,$65 ; 1,41$ \\
\hline Tem Filhos & & & & & & \\
\hline Sim & & 1 & & & 1 & \\
\hline Não & $0,000^{* * *}$ & 0,52 & 0,$47 ; 0,58$ & $0,000^{* * *}$ & 0,5 & 0,$46 ; 0,55$ \\
\hline Condição no domicílio & & & & & & \\
\hline Pessoa Responsável & & 1 & & & 1 & \\
\hline Cônjuge & $0,000^{* * *}$ & 1,62 & 1,$49 ; 1,77$ & $0,000^{* * *}$ & 1,30 & 1,$2 ; 1,4$ \\
\hline Filha & $0,000^{* * *}$ & 0,47 & 0,$41 ; 0,54$ & $0,000^{* * * *}$ & 0,44 & 0,$39 ; 0,50$ \\
\hline Outra & $0,000^{* * *}$ & 0,67 & 0,$56 ; 0,82$ & $0,000^{* * *}$ & 0,50 & 0,$42 ; 0,60$ \\
\hline Região & & & & & & \\
\hline São Paulo & & 1 & & & 1 & \\
\hline Belém & $0,000^{* * *}$ & 0,64 & 0,$54 ; 0,75$ & $0,000^{* * * *}$ & 1,96 & 1,$69 ; 2,26$ \\
\hline Fortaleza & 0,052 & 1,16 & 0,$99 ; 1,34$ & $0,000^{* * * *}$ & 2,69 & 2,$33 ; 3,12$ \\
\hline Recife & 0,059 & 1,15 & 0,$99 ; 1,33$ & $0,000^{* * * *}$ & 2,02 & 1,$75 ; 2,33$ \\
\hline Salvador & $0,000^{* * *}$ & 0,74 & 0,$64 ; 0,85$ & $0,000^{* * * *}$ & 1,49 & 1,$30 ; 1,71$ \\
\hline Belo Horizonte & $0,265^{* * *}$ & 0,91 & 0,$79 ; 1,06$ & $0,000^{* * *}$ & 1,79 & 1,$57 ; 2,04$ \\
\hline Rio de Janeiro & 0,246 & 0,92 & 0,$80 ; 1,05$ & $0,004^{* * *}$ & 1,20 & 1,$05 ; 1,37$ \\
\hline Curitiba & 0,003 & 0,77 & 0,$65 ; 0,91$ & 0,075 & 1,15 & 0,$98 ; 1,35$ \\
\hline Porto Alegre & 0,064 & 0,88 & 0,$78 ; 1,01$ & $0,000^{* * * *}$ & 1,42 & 1,$25 ; 1,60$ \\
\hline
\end{tabular}

Níveis de significância: ${ }^{* * *} \mathrm{p}$-valor $<0.001 ;{ }^{* *} \mathrm{p}$-valor $<0.01 ;{ }^{*} \mathrm{p}$-valor $<0.05$. 
No ano de 2002, as mulheres que trabalhavam até 20 horas por semana tinham três vezes mais chance de dedicar tempo acima da média em responsabilidades domésticas que as mulheres que trabalhavam de 40 a 44 horas por semana, e as que trabalhavam de 21 a 39 horas tinham duas vezes mais chance. Para o ano de 2012, as mulheres desses segmentos permanecem com maiores chances, mas mais reduzidas que as observadas para 2002. As primeiras apresentam duas vezes mais chance e as segundas, $67 \%$ a mais de chance de dedicar tempo acima da média em afazeres domésticos que aquelas que trabalham jornadas de 40 a 44 horas semanais. (Tabela 4)

\section{Considerações finais}

A tensão entre casa e trabalho não é uma questão nova, mas vários fatores imprimem significados diferentes para as gerações mais contemporâneas. A própria organização do tempo com o processo de modernização impôs jornadas bem definidas de trabalho, comprimindo cada vez mais os tempos dedicados a outros tipos de afazeres para além do trabalho. Mudanças na infraestrutura produtiva, nos processos de produção, inovações tecnológicas, avanço da urbanização, disseminação de novas ideias, valores e expectativas sociais que ocorridas de modo desigual ao largo do território, cobraram seu pedágio às mulheres, exigindo escolhas que envolveram ganhos, mas também perdas (OLIVEIRA; MARCONDES, 2004). As possibilidades de inserção produtiva para as mulheres se diversificam, em grande parte motivadas pela melhor qualificação escolar. Em tempos mais recentes isso tem levado as mulheres a penetrarem em nichos laborais até então considerados masculinos. Por outro lado, para alguns o modo como o mundo do trabalho se encontra organizado ainda preserva a lógica de trabalhadores - homens - dedicados quase que exclusivamente a suas obrigações produtivas. Mas de seres que necessitam ser complementados - por mulheres. Ou melhor, por atividades outras que a elas cabem desempenhar. Mantida 
essa lógica, quem seria o complementar das mulheres que estão no mercado de trabalho? Como diz um livro que trata do núcleo dessa questão, "as mulheres trabalhadores não têm esposas!" (APTER, 1985). Iniciativas como as chamadas jornadas flexíveis, o trabalho não manual em domicílio, reeditado ou repaginado graças à conectividade viabilizada pela internet de alta velocidade - sem que o trabalhador ou trabalhadora se isole de suas equipes de trabalho - são todas elas tentativas de enfrentar a questão do modelo em que se apoia o mercado de trabalho.

$O$ fato é que as mulheres sempre trabalharam, sendo formalmente considerado ou não como trabalho! Uma vasta literatura documenta o engajamento feminino em atividades que auxiliam no provimento de suas famílias ou até mesmo que lhes permitissem recursos fora do controle de pais ou maridos. E invariavelmente se envolviam, e podemos dizer que ainda se envolvem, em atividades que tornassem possível tocar as tarefas que "naturalmente" já lhes cabiam por serem mulheres. É plausível pensar nos múltiplos constrangimentos e prejuízos que tal condição ao longo do tempo acarretou. E que continua a acarretar na medida em que ainda se tem como natural que as mulheres assumam casa e família como sua responsabilidade primeira.

\section{Referências Bibliográficas}

APTER, T. Working Women don't have Wives. New York: St. Martin Press, 1985. 280 p.

BRUSCHINI, C. A bipolaridade do trabalho feminino no Brasil Contemporâneo. Cadernos de Pesquisa, FCC, n. 110, 2000.

. Trabalho e gênero no Brasil nos últimos dez anos. Cadernos de Pesquisa, FCC, São Paulo, v. 37, n. 132, p. 537-572, set./dez. 2007. . LOMBARDI, M. R. Instruídas e trabalhadeiras: trabalho

feminino no final do século XX. Cadernos Pagu, Campinas, 
n. 17/18, 2001.

RICOLDI, A. M. Articulação trabalho e família: famílias urbanas de baixa renda e políticas de apoio às trabalhadoras. São Paulo: Fundação Carlos Chagas, 2008. 147p.

. Família e trabalho: difícil conciliação para mães trabalhadoras de baixa renda. Cadernos de Pesquisa, FCC, v. 39, n. 136, jan./abr., 2009.

CASTRO, M. G; et al. Gênero e família em mudança: uma revisão com foco em cuidado parental. In: CASTRO, org. Dinâmica familiar do cuidado: afetos, imaginário e envolvimento dos pais na atenção aos filhos. Salvador: EDUFBA, 2012.

DEDECCA, C. S. Trabalho, tempo e gênero. In: COSTA, Ana Alice; OLIVEIRA, Eleonora M. de; LIMA, Maria E. B. de; SOARES, Vera. Reconfiguração das relações de gênero no trabalho, São Paulo: CUT Brasil, 2004.

DEDECCA, C.S. Regimes de trabalho, uso do tempo e desigualdade entre homens e mulheres. In: COSTA, Albertina Oliveira de; SORJ, Bila; BRUSCHINI, Cristina \& HIRATA, Helena. Mercado de trabalho e gênero: comparações internacionais. Rio de Janeiro: Editora Fundação Carlos Chagas, 2008a.

GUEDES, M. C. Mulheres de nível universitário no mercado de trabalho: aproximações do padrão masculino? In: ENCONTRO NACIONAL DE ESTUDOS POPULACIONAIS DA ABEP, 17, Caxambu, MG, 2010. Anais..., Caxambu: ABEP, 2010.

HIRATA, H. O universo do trabalho e da cidadania das mulheres: um olhar do feminismo e do sindicalismo. In: COSTA, A. A.; OLIVEIRA, E.M.; LIMA, M.E.B.; SOARES, V. (orgs.). Reconfiguração das relações de gênero e trabalho, editado pela CUT Brasil, 2004.

. Tempo, trabalho e gênero. In: COSTA, A. A.; OLIVEIRA, E. M.; LIMA, M. E. B.; SOARES, V. (Orgs.). Reconfiguração das relações de gênero e trabalho, editado pela CUT Brasil, 2004. 
. KERGOAT, D. Novas configurações da divisão sexual do trabalho. Cadernos de Pesquisa, FCC, v. 37, n. 132, set./dez., 2007.

MONTALI, L. Família e trabalho: os desafios da equidade para as famílias metropolitanas na recuperação da economia nos anos 2000. In: TURRA, C. M.; CUNHA, J. M. P. (orgs.) População e desenvolvimento em debate: contribuições da Associação Brasileira de Estudos Populacionais. Belo Horizonte: ABEP, 2012. pp. 177-186.

MONTALI, L. Provedoras e co-provedoras: mulheres-cônjuge e mulheres-chefe de família sob a precarização do trabalho e o desemprego. Revista Brasileira de Estudos Populacionais, v. 23, n. 2, jul./dez. 2006.

NEVES, M. de A. "Anotações sobre trabalho e gênero". In: Cadernos de Pesquisa, FCC, v. 43 n. 149, 2013, p. 404-421. 2013.

OAKLEY, A. The Sociology of Housework. New York: Pantheon Books, 1974. 1st American Edition. 243 p.

OLIVEIRA, M.C.F.A. Notas soltas sobre o mundo privado e os gêneros. In: TURRA, C. M.; CUNHA, J. M. P. (orgs.) População e desenvolvimento em debate: contribuições da Associação Brasileira de Estudos Populacionais. Belo Horizonte: ABEP, 2012b. pp. 163-170.

. Women's Status and Labor Regimes: the demand for fertility regulation. In: HOGAN, D. Population Change in Brazil: contemporary perspectives. Campinas: Population Studies Center NEPO/UNICAMP, 2001, p. 53-60.

- Condição feminina e alternativas de organização doméstica: as mulheres sem companheiro em São Paulo. In: Revista de Estudios Demográficos y Urbanos, México, DF: El Colegio de México, v. 7, n. 2-3, 1992, p. 511-537.

- Trabalho, família e condição feminina: considerações sobre a demanda por filhos. Revista Brasileira de Estudos de População, 6 (1), jan-jul: 25-33, 1989. 
A Produção da Vida: a mulher nas estratégias de sobrevivência da família trabalhadora na agricultura. Tese de Doutorado. Universidade de São Paulo, FFLCH, 1981

OLIVEIRA, M. C. F. A.; MARCONDES, G.S. Contabilizando perdas e ganhos: maternidade, trabalho e conjugalidade no pós-feminismo. In: XIV Encontro Nacional de Estudos Populacionais: Pobreza, desigualdade e exclusão social. Associação Brasileira de Estudos Populacionais (ABEP), Hotel Glória (Caxambu- MG). 20 a 24 de setembro de 2004.

SORJ, B.; FONTES, A.; MACHADO, D.C. Políticas e práticas de conciliação entre família e trabalho no Brasil. Cadernos de pesquisa, FCC, v. 37, n. 132, set./dez. 2007.

. et al. Políticas e Práticas de conciliação entre a família e o trabalho no Brasil. Cadernos de Pesquisa, v. 37, n. 132, set./dez. 2007, p. 573-594.

Arenas de cuidado nas interseções entre gênero e classe social no Brasil. In: Cadernos de Pesquisa, v. 43, n. 149, 2013, p. 478-491.

WAJNMAN, S. Relações familiares e diferenciais de rendimentos por sexo no Brasil. In: TURRA, C. M.; CUNHA, J. M. P. (orgs.) População e desenvolvimento em debate: contribuições da Associação Brasileira de Estudos Populacionais. Belo Horizonte: ABEP, 2012. pp. 187-192.

WAJNMAN, S. O crescimento da atividade feminina nos anos noventa no Brasil. In: ENCONTRO NACIONAL DE ESTUDOS POPULACIONAIS DA ABEP, 10, Caxambu, MG, 1998. Anais..., Caxambu: ABEP, 1998.

WAJNMAN, S; MARRI, I. Esposas como principais provedores de renda familiar. In: Anais... XV Encontro Nacional de Estudos Populacionais, ABEP: Caxambu, 2006. 
